\title{
Osteoimmune Interactions in Inflammatory Bowel Disease: Central Role of Bone Marrow Th17 TNFo Cells in Osteoclastogenesis
}

\author{
Abdelilah Wakkach ${ }^{1,2 *}$, Matthieu Rouleau ${ }^{1,2}$ and Claudine Blin-Wakkach ${ }^{1,2}$ \\ ${ }^{1}$ CNRS, UMR 7370, Laboratoire de PhysioMédecine Moléculaire (LP2M), Faculté de Médecine, Nice, France, ${ }^{2}$ University \\ Nice Sophia Antipolis, Nice, France
}

Osteoimmunology is an interdisciplinary research field dedicated to the study of the crosstalk between the immune and bone systems. $\mathrm{CD}^{+} \mathrm{T}$ cells are central players in this crosstalk. There is an emerging understanding that $C D 4^{+} \mathrm{T}$ cells play an important role in the bone marrow (BM) under physiological and pathological conditions and modulate the differentiation of bone-resorbing osteoclasts. However, identification of the mechanisms that maintain $\mathrm{CD}^{+}{ }^{+} \mathrm{T}$ cells in the BM is still a matter of investigation.

OPEN ACCESS

Edited by:

Francesca Di Rosa,

National Research Council, Italy

Reviewed by:

Britta Siegmund,

Charité - Universitätsmedizin Berlin,

Germany

Matthew Blake Greenblatt,

Weill Cornell Medical College, USA

${ }^{*}$ Correspondence:

Abdelilah Wakkach

wakkach@unice.fr

Specialty section:

This article was submitted to Immunological Memory,

a section of the journal

Frontiers in Immunology

Received: 25 September 2015 Accepted: 04 December 2015

Published: 18 December 2015

Citation:

Wakkach A, Rouleau M and Blin-Wakkach C (2015) Osteoimmune Interactions in Inflammatory Bowel

Disease: Central Role of Bone Marrow Th17 TNFo Cells in

Osteoclastogenesis.

Front. Immunol. 6:640. doi: 10.3389/fimmu.2015.00640
This article describes the $\mathrm{CD} 4{ }^{+} \mathrm{T}$ cell populations of the BM and reviews their role as osteoclastogenic population in inflammatory bowel disease.

Keywords: Th17 Cells, osteoclasts, bone marrow, inflammatory bowel diseases, osteoporosis, osteoimmunology

Bone marrow (BM) has long been known to play an important role in the immune system as a central hematopoietic organ. However, its function in T cell-mediated tolerance or immunity remains elusive. In the past, most of immunological studies were focused on $\mathrm{T}$ and $\mathrm{B}$ cells in the thymus, the lymph nodes, and the spleen considered as the central reservoirs of adaptive immunity. Over time, it became apparent that the immune system has a far more decentralized governing function. Recently, the BM was shown to play several unexpected roles, serving as an important reservoir for memory $\mathrm{T}$ cells including pathogenic cells and long-lived plasma cells involved in the maintenance of long-term immunity and pathogenicity.

\section{BONE MARROW RESIDENT CD4+ T CELLS}

Memory $\mathrm{CD} 4^{+} \mathrm{T}$ cells provide rapid and highly effective protective immunity against previously encountered pathogens and can recognize a wide variety of antigens. The concept of systemic memory consists of two major subsets: central memory $\mathrm{T}\left(\mathrm{T}_{\mathrm{CM}}\right)$ cells and effector memory $\mathrm{T}\left(\mathrm{T}_{\mathrm{EM}}\right)$ cells. Importantly, this identification was done in the blood (1). $\mathrm{T}_{\mathrm{CM}}$ cells express the chemokine receptor CCR7 and the vascular addressing $\mathrm{L}$ selectin $(\mathrm{CD} 62 \mathrm{~L})$, which enables them to migrate from the blood to the lymph nodes. $\mathrm{T}_{\mathrm{EM}}$ cells express low levels of CCR7 and CD62L but have receptors that allow them to access peripheral tissues as, for example, the E-selectin ligand cutaneous lymphocyte antigen (CLA), which grants them access to the skin, and $\alpha 4 \beta 7$, an integrin that allows them access to the gut. These memory $\mathrm{T}$ cells are called tissue-resident memory $\mathrm{T}$ cells $\left(\mathrm{T}_{\mathrm{RM}}\right)(2)$.

In the $\mathrm{BM}, \mathrm{T}$ cells represent about $3-8 \%$ of total nucleated cells. BM $\mathrm{T}$ cells reach the $\mathrm{BM}$ from the blood and, after homing to the BM, can move back to the blood to migrate to other lymphoid organs (3). The rules governing cell migration to the BM have been investigated mainly 
in the case of hematopoietic stem cells (HSCs) and revealed the dominant role of the CXCR4-CXCL12 axis in this migration. Analysis of $\mathrm{CD}^{+} \mathrm{T}$ cells from the $\mathrm{BM}$ of normal mice or mice affected with inflammatory bowel diseases (IBDs) showed the presence of both $\mathrm{T}_{\mathrm{CM}}$ and $\mathrm{T}_{\mathrm{EM}}$ cells that are characterized by a high expression of the chemokine receptors CXCR4 and CCR6 $(4,5)$. However, the mechanism of recruitment of these T cells in the $\mathrm{BM}$ remains elusive. Moreover, the degree to which memory cells are resident $\left(\mathrm{T}_{\mathrm{RM}}\right)$ within the $\mathrm{BM}$ versus transiting through it is less clear.

In order for $\mathrm{T}_{\mathrm{RM}}$ cells to be maintained in the $\mathrm{BM}$, they must adapt to the local environment and ignore signals that may induce their egress outside of the BM. The mechanisms and cells involved in the maintenance of BM T cells represent a matter of active research. BM stroma includes mesenchymal stromal cells (MSCs), endothelial cells, osteoblasts (OBLs), and adipocytes. This stromal cell heterogeneity complicates the understanding of the implication of these cells in the maintenance of immunological memory. It is well recognized that BM stromal cells support hematopoiesis by establishing specialized niches. These niches regulate the fate of HSCs in terms of quiescence, migration, and differentiation (6). The major components of the HSC niches include several MSC populations [CXC12-abundant reticular (CAR) cells and Nestin ${ }^{+}$cells] (7), OBLs $(8,9)$, and endothelial cells $(10,11)$. In addition, regulatory $\mathrm{T}$ cells $(12)$, macrophages (13), and osteoclasts (OCLs) $(14,15)$ were shown to contribute to the regulation of the HSC niches. MSCs have also been involved in the retention of $\mathrm{T}$ cells in the BM. Tokoyoda et al. showed that memory $\mathrm{CD}^{+} \mathrm{T}$ cells are located close to $\mathrm{BM}$ stromal cells expressing IL-7 and VCAM1 (16). This was confirmed by Nemoto et al. who reported that in IBD, pathogenic $\mathrm{CD} 4^{+} \mathrm{T}$ cells are retained in the $\mathrm{BM}$ through interactions with IL-7-producing MSCs (17). However, the exact nature of the VCAM1 ${ }^{+}$and $\mathrm{IL}-7^{+}$ stromal cells and their role in the maintaining of memory $\mathrm{CD} 4^{+}$ $\mathrm{T}$ cells remain to be elucidated. Adoptive transfer of $\mathrm{B}$ and $\mathrm{T}$ lymphocytes in mice led to seeding of dendritic cell (DC) clusters with grafted cells in perivascular domains, which were referred to as BM immune niches (18). Overall, these observations suggested the existence of $\mathrm{CD}^{+} \mathrm{T}$ cell niches that remain to be characterized in term of cell composition and regulation. The identification of BM immune niches raises many new questions. Which molecules regulate $\mathrm{T}$ cell migration? How are memory $\mathrm{CD} 4^{+} \mathrm{T}$ cells maintained and for how long? How do they interact with BM stroma under physiological and inflammatory conditions? The identification of BM-specific factors that control $\mathrm{T}$ cell functions is likely to have a major impact on translational medicine.

\section{CROSSTALK BETWEEN CD4 ${ }^{+}$T CELLS AND BONE CELLS}

The crosstalk between the immune and bone systems led to the emergence of an interdisciplinary field called osteoimmunology (19). This field emerged from clinical observations reporting that patients presenting an overactivation of the immune system, such as chronic infections and chronic inflammatory diseases, also display bone loss (20-22). The importance of this crosstalk was further confirmed with the identification of the role of activated $\mathrm{CD}^{+} \mathrm{T}$ cells in pathological osteoclastogenesis (23). Its scope has been extended to encompass a wide range of molecular and cellular interactions, including those between immune cells and bone cells, and between bone cells and hematopoietic cells. These interactions are essential for the development of the immune and bone systems $(15,24)$.

Bone remodeling is a highly regulated process involving complex interactions between the activity of the bone-forming OBLs and the activity of the bone-resorbing OCLs. OCLs are multinucleated cells from the myeloid lineage (monocytes and DCs) (25) that degrade the bone matrix and release growth factors that contribute to the coupling between OCLs and OBLs (26). The mesenchymal-derived OBLs migrate to the eroded sites and initiate new bone formation by the secretion of an extracellular matrix and its calcification. In a physiological state, bone remodeling provides an adequate environment for the development of the immune system and the protection of HSCs (6).

The $\mathrm{BM}$ represents a reservoir for memory $\mathrm{T}$ cells among which $25 \%$ are Foxp $3^{+}$regulatory T cells (27). It is also a preferential site for the migration or the selective retention and function of regulatory $\mathrm{T}$ cells. This finding provides evidence for an unidentified role of the BM in T-cell homeostasis. Moreover, Tokoyoda et al. have shown that in adult mice, more than $80 \%$ of antigen specific memory $\mathrm{CD} 4^{+} \mathrm{T}$ cells rest in the $\mathrm{BM}$ for more than 90 days after immunization and do not proliferate (16). From these observations, we can hypothesize that the immunosuppressive activity of BM regulatory $\mathrm{T}$ cells participates in the quiescence of memory $\mathrm{T}$ cells as recently shown for $\mathrm{CD}^{+}$ memory $\mathrm{T}$ cells (28). In this study, regulatory $\mathrm{T}$ cells suppress proliferation and effector programs during the memory differentiation of $\mathrm{CD}^{+} \mathrm{T}$ cells in the lymph nodes (28). In addition to regulatory $\mathrm{T}$ cells, MSCs are also generally considered as immunosuppressive cells. MSCs may suppress T-lymphocyte proliferation and functions both in vitro and in vivo $(29,30)$. They produce soluble factors, including TGF- $\beta$, able to mediate suppression of T-cell proliferation (31). MSCs can also inhibit $\mathrm{T}$ cell proliferation by increasing IL-10 secretion (31). These properties suggest that the immunosuppressive effect of MSCs may participate to the preservation of $\mathrm{CD}^{+}$memory $\mathrm{T}$ cells in the BM. However, MSCs are a heterogeneous population of cells and their immune suppressive activity has mainly been explored in pathological conditions. It is therefore important to better understand this function to clarify how MSCs may control the quiescence and niche of $\mathrm{CD} 4^{+} \mathrm{T}$ cells.

To date, the role of $\mathrm{CD}^{+}$regulatory $\mathrm{T}$ cells and memory $\mathrm{T}$ cells on bone cells in physiological conditions remains controversial. It has been reported that Rag1 $1^{-/-}$mice lacking $\mathrm{T}$ cells have a normal bone phenotype (32), whereas $\mathrm{T}$ cell-deficient nude mice display, with age, an increased bone resorption and a decreased bone mineral density (33). T cells are capable of mediating anti-osteoclastogenic signals, as depletion of CD4 and CD8 T lymphocytes in mice in vivo enhances vitamin D3-stimulated OCL formation by blocking the production of osteoprotegerin (OPG) by B cells (34). These observations revealed the difficulty to conclude on the role of $\mathrm{CD} 4^{+} \mathrm{T}$ cells in steady state osteoclastogenesis because they can have direct and indirect effects on 
OCL precursors and also because of their heterogeneity. Indeed, Th1, Th2, and Th17 cells have been reported to have opposite effects on OCL differentiation in vitro. Th1 and Th2 cells inhibit OCL formation through their production of INF- $\gamma$ and IL-4, respectively, whereas Th17 cells have an osteoclastogenic helper effect in vitro mediated by MSCs (35).

\section{OSTEOIMMUNOLOGY INTERACTIONS IN INFLAMMATORY BOWEL DISEASE}

Inflammatory bowel diseases are inflammatory diseases that affect the gastrointestinal tract. There are two main clinical forms of IBD: Crohn's disease which affects any part of gastrointestinal tract and ulcerative colitis in which the pathology mostly affects the colonic mucosa (36). Several factors including genetic factors, gut microbiota, and the host immune system have been described to contribute to IBD (36). Moreover, these diseases are often associated with extra-intestinal manifestations, in particular, bone loss. Indeed, more than $40 \%$ of patients with IBD also present bone loss that remains a major extra-intestinal cause of morbidity leading to an impaired quality of life and productivity (37). The prevalence of osteopenia and osteoporosis in patients presenting with IBD ranges from $22-77 \%$ to $17-41 \%$, respectively, depending on the population location or the study design. According to the WHO, osteoporosis is defined as a systemic skeletal disease that occurs when bone resorption exceeds bone formation. In low-turnover osteoporosis, bone resorption is normal whereas the synthesis of bone tissue is reduced. In contrast, in high-turnover osteoporosis, the activity of OCL is increased. Osteoporosis associated with chronic inflammation usually follows the high-turnover pattern, whereas corticosteroid-induced osteoporosis is usually of the low-turnover pattern (38).

The association between chronic inflammation and bone destruction has been recognized a long time ago, leading to the hypothesis of the participation of immune cells in the control of bone remodeling (19). A seminal work published in 1999 by Kong et al. established the role of $\mathrm{CD} 4^{+} \mathrm{T}$ cells in inflammatory osteoclastogenesis. In this study, the authors demonstrated that activated $\mathrm{CD}^{+} \mathrm{T}$ cells produce RANKL and induce the differentiation of OCLs in vitro (23). Besides that, $\mathrm{ctla}^{-/-}$mice, in which $\mathrm{T}$ cells are spontaneously activated, displayed a severe osteoporo-

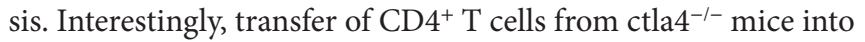
lymphocyte-deficient rag $1^{-/-}$mice caused bone destruction that can be reversed through inhibition of RANKL by OPG (23). One additional study confirmed these observations and identified a common causal link between intestinal inflammation and bone loss showing that activated $\mathrm{T}$ cells producing RANKL accumulate in the BM during intestinal inflammation (39). Taken together, these studies suggest that pathogenic $\mathrm{CD} 4^{+} \mathrm{T}$ cells present in the $\mathrm{BM}$ during IBD are potentially osteoclastogenic.

Using a mouse model of colitis, induced in SCID mice by injection of $\mathrm{CD}^{+} \mathrm{CD} 45 \mathrm{RBhigh}$ naive $\mathrm{T}$ cells, Nemoto et al. found that a large number of $\mathrm{CD} 4{ }^{+} \mathrm{CD} 44^{+} \mathrm{CD} 62 \mathrm{~L}^{-}$memory $\mathrm{T}$ cells resides in the BM. Transfer of BM memory $\mathrm{CD} 4^{+} \mathrm{T}$ cells into new recipient SCID mice reproduced colitis. These $\mathrm{BM} \mathrm{CD} 4^{+}$ cells of colitic mice have therefore been described as "colitogenic memory T cells" (5). Importantly, these resident BM CD4 ${ }^{+}$ memory $\mathrm{T}$ cells are closely associated with IL-7-producing stromal cells, and they cannot induce colitis when transferred into IL- $7^{-/-} \times \mathrm{Rag}^{-/-}$mice, suggesting that IL-7 plays an essential role in their maintenance or survival in the BM (5). Recently, the same group has demonstrated that BM MSCs are the major source of IL-7 and play a pathological role in IBD by forming the niche for these colitogenic $\mathrm{CD}^{+}$memory $\mathrm{T}$ cells (17). However, their osteoclastogenic effect has not been explored.

Although IBD has traditionally been assumed to be a Th1dependent disease, there is controversy over the role of Th1 on bone homeostasis. IFN- $\gamma$ has been shown to directly inhibit osteoclastogenesis by interfering with the RANKL-RANK signaling pathway (40). Moreover, in vitro differentiated $\mathrm{CD}^{+} \mathrm{Th} 1$ cells have been shown to inhibit OCL formation through their canonical production of IFN- $\gamma$ (35). In contrast, observations in humans suggested that IFN- $\gamma$ may promote osteoclastogenesis because it improves bone resorption in osteopetrotic patients treated with IFN- $\boldsymbol{\gamma}$ (41). IFN- $\boldsymbol{\gamma}$ is also a physiologic inducer of MHC class II expression by APCs resulting in the activation of $\mathrm{T}$ cells that induce bone resorption by their secretion of RANKL and TNF- $\alpha$ (42). Together, these data suggest that IFN- $\gamma$ inhibits OCL formation through direct targeting of maturing OCLs, while it promotes osteoclastogenesis indirectly by stimulating $\mathrm{T}$ cell activation.

Nowadays, it is well known that the inflamed gastrointestinal mucosa of patients with IBD is massively infiltrated with Th17 cells and that Th17-related cytokines are produced in excess (43). Based on this, it is obvious that Th17 cells play an important role in the pathogenesis of IBD, which was previously solely attributed to Th1 cells. However, although a pathogenic role in intestine inflammation has been ascribed to Th17 cells, administration of neutralizing anti-IL-17A antibody to patients with Crohn's disease did not show any therapeutic benefit (44). Moreover, in some patients, it exacerbated the disease suggesting a protective role of IL-17A (44). Thus, despite the role of Th17 cytokines is important in many aspects of intestinal homeostasis and protection from mucosal pathogens, their role in the pathogenesis of IBD remains ambiguous. However, IL-17 represents a potent osteoclastogenic cytokine, and its receptors are expressed by many cell types, including OBLs and OCLs (45). Kotake et al. reported that IL-17 is abundant in rheumatoid synovial fluid and that IL-17 stimulates OCL differentiation by inducing RANKL expression by OBLs (46). It should be noted that the effect of IL-17 is not limited to this direct action on the OBLs. IL-17 facilitates local inflammation by recruiting and activating immune cells, which leads to an abundance of inflammatory cytokines such as TNF- $\alpha$ (46). IL-17-deficient mice are resistant to bone destruction induced by LPS (35). Otherwise, Oostlander et al. suggested a particular role for IL-17 in osteoclastogenesis in Crohn's disease patients (47). More recently, we have shown that BM Th17 T cells expressing high levels of TNF $\alpha$ were able to induce OCL differentiation in IBD mice. This T-cell-induced OCL differentiation could be inhibited by IL-17 blockade (4) suggesting the importance of IL-17A in osteoporosis. 
A picture emerged from the literature $(48,49)$ to define what we believe to be osteoclastogenic T cells: first, osteoclastogenic $\mathrm{T}$ cells should not produce a large amount of IFN- $\gamma$. Second, they should trigger local inflammation and the production of inflammatory cytokines, including TNF- $\alpha$, that induce RANK-L expression on MSCs. Third, they should express RANK-L and might directly participate in the increase of osteoclastogenesis.

Recent data indicate that in IBD, Th17 cells-producing TNF$\alpha$ represent the long-sought-after osteoclastogenic $\mathrm{T}$ cell subset that fulfills all the criteria mentioned above $(4,50)$. In murine models of IBD associated with bone loss, we have shown that Th17-producing TNF- $\alpha$ cells accumulate in the BM, the colon, and spleen and have a potent capacity to induce OCL differentiation without addition of any exogenic osteoclastogenic factors (4). Through their production of RANK-L and TNF $\alpha$, Th17 cells directly induce the differentiation of precursors into OCLs (4), but they also have a major effect on MSCs through their production of IL-17. Indeed, IL-17 increases RANK-L expression in MSCs leading to increased OCL formation (4, $35,46)$. Moreover, in the context of IBD, Th17 cells increase the expression of monocyte chemoattractant protein-1 (MCP-1) and macrophage inflammatory protein $1 \alpha$ (MIP- $1 \alpha)$ by MSCs, which may promote the recruitment of inflammatory monocytes (OCL precursors) in the BM and their differentiation into OCLs (4). To translate these finding into human disease, IL-17-producing $\mathrm{T}$ cells from the blood of IBD patients are osteoclastogenic cells in vitro and increase MIP- $1 \alpha$ and MCP- 1 expression by human MSCs $(4,47)$, suggesting their participation to osteoporosis in these patients. Therefore, Th17 cells represent a key target for innovative therapeutic approaches for IBD-associated bone destruction.

\section{CONCLUDING REMARKS}

Recent advances have contributed to our understanding of the biology of $\mathrm{CD}^{+} \mathrm{T}$ cells in the BM. These $\mathrm{T}$ cells fulfill both homeostatic and pathological functions with respect to the bone system. IBD is an immune-mediated disease characterized by systemic Th1 and Th17 responses and bone destruction. Recent studies have revealed that Th17 cells are not only required for the initiation of systemic immune response as they are critical regulators in the chronic inflammation associated with bone destruction, particularly in rheumatoid arthritis. Our recent findings extend these observation to IBD in which the site of inflammation

\section{REFERENCES}

1. Sallusto F, Lenig D, Förster R, Lipp M, Lanzavecchia A. Two subsets of memory $\mathrm{T}$ lymphocytes with distinct homing potentials and effector functions. Nature (1999) 401:708-12. doi:10.1038/44385

2. Mueller SN, Gebhardt T, Carbone FR, Heath WR. Memory T cell subsets, migration patterns, and tissue residence. Annu Rev Immunol (2013) 31:137-61. doi:10.1146/annurev-immunol-032712-095954

3. Di Rosa F, Pabst R. The bone marrow: a nest for migratory memory T cells. Trends Immunol (2005) 26:360-6. doi:10.1016/j.it.2005.04.011

4. Ciucci T, Ibáñez L, Boucoiran A, Birgy-Barelli E, Pène J, Abou-Ezzi G, et al. Bone marrow Th17 TNF $\alpha$ cells induce osteoclast differentiation,

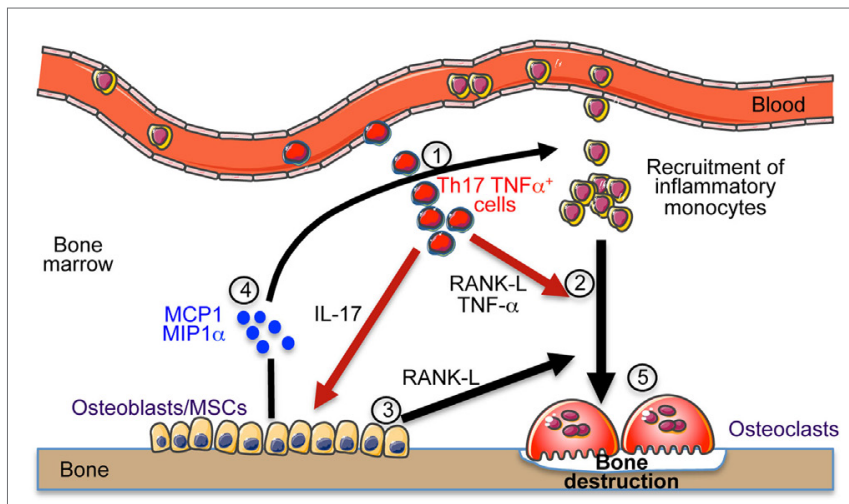

FIGURE 1 | Th17 cells induce bone destruction in IBD. In IBD, Th17 TNF $\alpha$ cells migrate and accumulate in the bone marrow (1). They express RANK-L and TNF- $\alpha$ that participate to osteoclast differentiation (2). They also express IL-17 that stimulates the local inflammation and activates osteoblasts to produce RANK-L inducing osteoclast formation (3) and MCP-1 and MIP- $1 \alpha$ chemokines (4) participating to the recruitment of osteoclast precursor cells (monocytes) in the BM that contribute to the increased osteoclastogenesis (5) and to bone destruction.

is far from the bone and provide the first characterization of osteoclastogenic Th17 TNF- $\alpha^{+}$cells in the BM linking IBD and bone destruction.

Collectively, we propose that these osteoclastogenic cells, once in the BM, enable the secretion of chemokines and RANKL by stromal cells. This enhances the recruitment of inflammatory monocytes and DCs that differentiate into OCLs and increase the bone resorption leading to osteoporosis as illustrated in Figure 1.

\section{AUTHOR CONTRIBUTIONS}

AW wrote and reviewed the manuscript. CB-W and MR reviewed the manuscript.

\section{ACKNOWLEDGMENTS}

The work of the authors was supported by the "Fondation pour la Recherche Médicale" (Equipe FRM DEQ20130326467), the "Agence Nationale de la Recherche" (ANR), the "Arthritis Fondation," the "Société Française de Rhumatologie" and the "Société Francophone du Diabète" (SFD).

and link bone destruction to IBD. Gut (2015) 64:1072-81. doi:10.1136/ gutjnl-2014-306947

5. Nemoto Y, Kanai T, Makita S, Okamoto R, Totsuka T, Takeda K, et al. Bone marrow retaining colitogenic $\mathrm{CD} 4+\mathrm{T}$ cells may be a pathogenic reservoir for chronic colitis. Gastroenterology (2007) 132:176-89. doi:10.1053/j. gastro.2006.10.035

6. Scadden DT. Nice neighborhood: emerging concepts of the stem cell niche. Cell (2014) 157:41-50. doi:10.1016/j.cell.2014.02.013

7. Schajnovitz A, Itkin T, D'Uva G, Kalinkovich A, Golan K, Ludin A, et al. CXCL12 secretion by bone marrow stromal cells is dependent on cell contact and mediated by connexin-43 and connexin-45 gap junctions. Nat Immunol (2011) 12:391-8. doi:10.1038/ni.2017 
8. Calvi LM, Adams GB, Weibrecht KW, Weber JM, Olson DP, Knight MC, et al. Osteoblastic cells regulate the haematopoietic stem cell niche. Nature (2003) 425:841-6. doi:10.1038/nature02040

9. Zhang J, Niu C, Ye L, Huang H, He X, Tong W-G, et al. Identification of the haematopoietic stem cell niche and control of the niche size. Nature (2003) 425:836-41. doi:10.1038/nature02041

10. Butler JM, Nolan DJ, Vertes EL, Varnum-Finney B, Kobayashi H, Hooper AT, et al. Endothelial cells are essential for the self-renewal and repopulation of Notch-dependent hematopoietic stem cells. Cell Stem Cell (2010) 6:251-64. doi:10.1016/j.stem.2010.02.001

11. Ding L, Saunders TL, Enikolopov G, Morrison SJ. Endothelial and perivascular cells maintain haematopoietic stem cells. Nature (2012) 481:457-62. doi:10.1038/nature10783

12. Fujisaki J, Wu J, Carlson AL, Silberstein L, Putheti P, Larocca R, et al. In vivo imaging of Treg cells providing immune privilege to the haematopoietic stemcell niche. Nature (2011) 474:216-9. doi:10.1038/nature10160

13. Chow A, Lucas D, Hidalgo A, Méndez-Ferrer S, Hashimoto D, Scheiermann $\mathrm{C}$, et al. Bone marrow $\mathrm{CD} 169+$ macrophages promote the retention of hematopoietic stem and progenitor cells in the mesenchymal stem cell niche. J Exp Med (2011) 208:261-71. doi:10.1084/jem.20101688

14. Kollet O, Dar A, Shivtiel S, Kalinkovich A, Lapid K, Sztainberg Y, et al. Osteoclasts degrade endosteal components and promote mobilization of hematopoietic progenitor cells. Nat Med (2006) 12:657-64. doi:10.1038/ $\mathrm{nm} 1417$

15. Mansour A, Abou-Ezzi G, Sitnicka E, Jacobsen SEW, Wakkach A, BlinWakkach C. Osteoclasts promote the formation of hematopoietic stem cell niches in the bone marrow. J Exp Med (2012) 209:537-49. doi:10.1084/ jem.20110994

16. Tokoyoda K, Zehentmeier S, Hegazy AN, Albrecht I, Grün JR, Löhning $\mathrm{M}$, et al. Professional memory CD4+ T lymphocytes preferentially reside and rest in the bone marrow. Immunity (2009) 30:721-30. doi:10.1016/j. immuni.2009.03.015

17. Nemoto Y, Kanai T, Takahara M, Oshima S, Nakamura T, Okamoto R, et al. Bone marrow-mesenchymal stem cells are a major source of interleukin-7 and sustain colitis by forming the niche for colitogenic CD4 memory T cells. Gut (2013) 62:1142-52. doi:10.1136/gutjnl-2012-302029

18. Sapoznikov A, Pewzner-Jung Y, Kalchenko V, Krauthgamer R, Shachar I, Jung S. Perivascular clusters of dendritic cells provide critical survival signals to B cells in bone marrow niches. Nat Immunol (2008) 9:388-95. doi:10.1038/ ni1571

19. Arron JR, Choi Y. Osteoimmunology: bone versus immune system. Nature (2000) 408:535-6. doi:10.1038/35046196

20. Stellon AJ, Davies A, Compston J, Williams R. Bone loss in autoimmune chronic active hepatitis on maintenance corticosteroid therapy. Gastroenterology (1985) 89:1078-83.

21. Feldmann M, Brennan FM, Maini RN. Role of cytokines in rheumatoid arthritis. Annu Rev Immunol (1996) 14:397-440. doi:10.1146/annurev. immunol.14.1.397

22. Piepkorn B, Kann P, Forst T, Andreas J, Pfützner A, Beyer J. Bone mineral density and bone metabolism in diabetes mellitus. Horm Metab Res (1997) 29:584-91. doi:10.1055/s-2007-979106

23. Kong Y-Y, Feige U, Sarosi I, Bolon B, Tafuri A, Morony S, et al. Activated $\mathrm{T}$ cells regulate bone loss and joint destruction in adjuvant arthritis through osteoprotegerin ligand. Nature (1999) 402:304-9. doi:10.1038/46303

24. Blin-Wakkach C, Wakkach A, Quincey D, Carle GF. Interleukin-7 partially rescues $\mathrm{B}$-lymphopoiesis in osteopetrotic oc/oc mice through the engagement of B220+ CD11b+ progenitors. Exp Hematol (2006) 34:851-9. doi:10.1016/j. exphem.2006.04.003

25. Wakkach A, Mansour A, Dacquin R, Coste E, Jurdic P, Carle GF, et al. Bone marrow microenvironment controls the in vivo differentiation of murine dendritic cells into osteoclasts. Blood (2008) 112:5074-83. doi:10.1182/ blood-2008-01-132787

26. Tang Y, Wu X, Lei W, Pang L, Wan C, Shi Z, et al. TGF-beta1-induced migration of bone mesenchymal stem cells couples bone resorption with formation. Nat Med (2009) 15:757-65. doi:10.1038/nm.1979

27. Zou L, Barnett B, Safah H, Larussa VF, Evdemon-Hogan M, Mottram P, et al. Bone marrow is a reservoir for $\mathrm{CD} 4+\mathrm{CD} 25+$ regulatory $\mathrm{T}$ cells that traffic through CXCL12/CXCR4 signals. Cancer Res (2004) 64:8451-5. doi:10.1158/0008-5472.CAN-04-1987

28. Kalia V, Penny LA, Yuzefpolskiy Y, Baumann FM, Sarkar S. Quiescence of memory $\mathrm{CD} 8(+) \mathrm{T}$ cells is mediated by regulatory $\mathrm{T}$ cells through inhibitory receptor CTLA-4. Immunity (2015) 42:1116-29. doi:10.1016/j. immuni.2015.05.023

29. Nauta AJ, Fibbe WE. Immunomodulatory properties of mesenchymal stromal cells. Blood (2007) 110:3499-506. doi:10.1182/blood-2007-02-069716

30. Anderson P, Souza-Moreira L, Morell M, Caro M, O’Valle F, Gonzalez-Rey E, et al. Adipose-derived mesenchymal stromal cells induce immunomodulatory macrophages which protect from experimental colitis and sepsis. Gut (2013) 62:1131-41. doi:10.1136/gutjnl-2012-302152

31. Sioud M. New insights into mesenchymal stromal cell-mediated T-cell suppression through galectins. Scand J Immunol (2011) 73:79-84. doi:10.1111/j.1365-3083.2010.02491.x

32. Anginot A, Dacquin R, Mazzorana M, Jurdic P. Lymphocytes and the Dap12 adaptor are key regulators of osteoclast activation associated with gonadal failure. PLoS One (2007) 2:e585. doi:10.1371/journal.pone.0000585

33. Li Y, Toraldo G, Li A, Yang X, Zhang H, Qian W-P, et al. B cells and T cells are critical for the preservation of bone homeostasis and attainment of peak bone mass in vivo. Blood (2007) 109:3839-48. doi:10.1182/ blood-2006-07-037994

34. Grcević D, Lee SK, Marusić A, Lorenzo JA. Depletion of CD4 and CD8 T lymphocytes in mice in vivo enhances 1,25-dihydroxyvitamin D3-stimulated osteoclast-like cell formation in vitro by a mechanism that is dependent on prostaglandin synthesis. J Immunol (2000) 165:4231-8.

35. Sato K, Suematsu A, Okamoto K, Yamaguchi A, Morishita Y, Kadono Y, et al. Th17 functions as an osteoclastogenic helper $\mathrm{T}$ cell subset that links $\mathrm{T}$ cell activation and bone destruction. J Exp Med (2006) 203:2673-82. doi:10.1084/ jem.20061775

36. Maloy KJ, Powrie F. Intestinal homeostasis and its breakdown in inflammatory bowel disease. Nature (2011) 474:298-306. doi:10.1038/nature10208

37. Tilg H, Moschen AR, Kaser A, Pines A, Dotan I. Gut, inflammation and osteoporosis: basic and clinical concepts. Gut (2008) 57:684-94. doi:10.1136/ gut.2006.117382

38. Raisz LG. Pathogenesis of osteoporosis: concepts, conflicts, and prospects. $J$ Clin Invest (2005) 115:3318-25. doi:10.1172/JCI27071

39. Ashcroft AJ, Cruickshank SM, Croucher PI, Perry MJ, Rollinson S, Lippitt $\mathrm{JM}$, et al. Colonic dendritic cells, intestinal inflammation, and T cell-mediated bone destruction are modulated by recombinant osteoprotegerin. Immunity (2003) 19:849-61. doi:10.1016/S1074-7613(03)00326-1

40. Takayanagi H, Ogasawara K, Hida S, Chiba T, Murata S, Sato K, et al. T-cellmediated regulation of osteoclastogenesis by signalling cross-talk between RANKL and IFN-gamma. Nature (2000) 408:600-5. doi:10.1038/35046102

41. Key LL, Rodriguiz RM, Willi SM, Wright NM, Hatcher HC, Eyre DR, et al. Long-term treatment of osteopetrosis with recombinant human interferon gamma. N Engl J Med (1995) 332:1594-9. doi:10.1056/ NEJM199506153322402

42. Gao Y, Grassi F, Ryan M, Pacifici R. IFN-gamma stimulates osteoclast formation and bone loss in vivo via antigen-driven $\mathrm{T}$ cell activation. J Clin Invest (2007) 117(1):122-32. doi:10.1172/JCI30074

43. Ray S, De Salvo C, Pizarro TT. Central role of IL-17/Th17 immune responses and the gut microbiota in the pathogenesis of intestinal fibrosis. Curr Opin Gastroenterol (2014) 30:531-8. doi:10.1097/MOG.0000000000000119

44. Hueber W, Sands BE, Lewitzky S, Vandemeulebroecke M, Reinisch W, Higgins PDR, et al. Secukinumab, a human anti-IL-17A monoclonal antibody, for moderate to severe Crohn's disease: unexpected results of a randomised, double-blind placebo-controlled trial. Gut (2012) 61:1693-700. doi:10.1136/ gutjnl-2011-301668

45. Van bezooijen RL, Farih-Sips HC, Papapoulos SE, Löwik CW. Interleukin-17: a new bone acting cytokine in vitro. J Bone Miner Res (1999) 14:1513-21. doi:10.1359/jbmr.1999.14.9.1513

46. Kotake $\mathrm{S}$, Udagawa $\mathrm{N}$, Takahashi $\mathrm{N}$, Matsuzaki $\mathrm{K}$, Itoh $\mathrm{K}$, Ishiyama $\mathrm{S}$, et al. IL-17 in synovial fluids from patients with rheumatoid arthritis is a potent stimulator of osteoclastogenesis. J Clin Invest (1999) 103:1345-52. doi:10.1172/JCI5703

47. Oostlander AE, Everts V, Schoenmaker T, Bravenboer N, van Vliet SJ, van Bodegraven AA, et al. T cell-mediated increased osteoclast formation from 
peripheral blood as a mechanism for Crohn's disease-associated bone loss. $J$ Cell Biochem (2012) 113:260-8. doi:10.1002/jcb.23352

48. Takayanagi H. Osteoimmunology: shared mechanisms and crosstalk between the immune and bone systems. Nat Rev Immunol (2007) 7:292-304. doi:10.1038/nri2062

49. Jones D, Glimcher LH, Aliprantis AO. Osteoimmunology at the nexus of arthritis, osteoporosis, cancer, and infection. J Clin Invest (2011) 121:2534-42. doi:10.1172/JCI46262

50. Syrbe U, Siegmund B. Bone marrow Th17 TNF $\alpha$ cells induce osteoclast differentiation and link bone destruction to IBD. Gut (2015) 64:1011-2. doi:10.1136/gutjnl-2014-308436
Conflict of Interest Statement: The authors declare that the research was conducted in the absence of any commercial or financial relationships that could be construed as a potential conflict of interest.

Copyright (c) 2015 Wakkach, Rouleau and Blin-Wakkach. This is an open-access article distributed under the terms of the Creative Commons Attribution License (CC BY). The use, distribution or reproduction in other forums is permitted, provided the original author(s) or licensor are credited and that the original publication in this journal is cited, in accordance with accepted academic practice. No use, distribution or reproduction is permitted which does not comply with these terms. 